
\title{
$\begin{array}{ll}\text { Research Square } & \begin{array}{l}\text { Preprints are preliminary reports that have not undergone peer review. } \\ \text { They should not be considered conclusive, used to inform clinical practice, } \\ \text { or referenced by the media as validated information. }\end{array}\end{array}$
}

\section{Trade Openness and Urbanization impact on Renewable and Non- Renewable Energy Consumption in China}

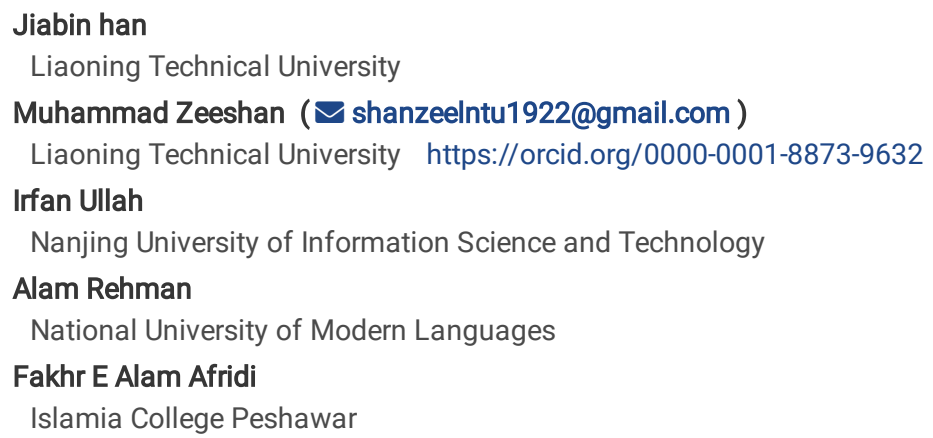

Version of Record: A version of this preprint was published at Environmental Science and Pollution Research on January 30th, 2022. See the published version at https://doi.org/10.1007/s11356-021-18353-x. 


\section{Abstract}

This study investigates the trade openness and urbanization effect on renewable and non-renewable energy consumption in China for the period 19902018. We apply the Quantile Regression technique for the analysis, our results show that trade significantly increases the non-renewable energy consumption in all quintiles while partially increases renewable energy consumption. This shows that trade activities in production and export commodities heavily rely on non-renewable energy inputs instead of renewable energy inputs. Urbanization affects non-renewable energy consumption only in three quintiles, while its effect is insignificant in most of the quintiles. Similarly, Urbanization does not affect renewable energy consumption as in almost all quantiles the coefficients are statistically insignificant. This implies that urbanization is one of the determinant of energy consumption in China. The empirical findings of this study suggest some policy recommendations; first, the government needs to implement certain regulations while expanding trade to minimize the negative effect of non-renewable energy consumption; besides government should provide incentives to industrial units and traders for using renewable energy which may help to attain long term sustainable development goals.

\section{Introduction}

China is among the largest energy consumers in the world, and its trade openness, industrialization, and urbanization are the main factors that account for high energy consumption. Energy consumption plays an important role in the development of an economy, however, energy consumption and production contain some externalities, such as pollution and greenhouse gases, which eventually undermine economic sustainability (Shi, 2015). Trade openness and urbanization policies may have potential implications for the energy consumption and sustainable growth of the economy. Therefore, it is essential to understand the relationship between trade openness and energy consumption. Besides, trade and energy consumption have crucial importance for several reasons, such as the inefficient energy policy may lead to lower trade and economic activities, (b)s the energy conservation policies that reduce the energy consumption will counterbalance the trade liberalization policies developed to promote the economic activity (Koengkan, 2018; Sadorsky, 2014b), (c) there is a unidirectional relationship from trade to energy consumption which indicates that trade policy increases energy consumption while conservation policies will not affect the liberalization policies. Trade openness may influence the country's energy consumption due to an increase in economic activities. The export sector especially the industrial export expansion increases the demand for consumption.

Apart from the above reasons, trade openness allows the country to import commodities that may cause high energy consumption, for example, automobile, industrial inputs, etc. Moreover, the income effect is also one the main cause of high energy consumptions that especially resulted due to the trade liberalization; as trade account for a rise in the income of the people that would account for adaptation of complimentary technological equipment that requires a high level of energy consumption. Trade openness increases energy consumption both in the long run and short run in the context of Middle Eastern Countries; mainly due to the positive effect of imports and exports and economic activities (Sadorsky, 2011).

Urbanization is commonly termed as an essential driving force that accounts for more energy consumption, $\mathrm{CO}_{2}$ emissions, industrial development, and improvement in living conditions. In 1960, the urban population at the global level was $34 \%$ of the total; however, by 2014 , it accounted to grow for $54 \%$ of the total countries. This increasing urbanization ongoing growth of the world's population and expecting an increase of 2.5 billion more people by the year 2050, according to United Nations forecast is expected to add up in the urban population, of which Asia and Africa are among the top of the list. Moreover, by 2030, 24 mega-cities will be added to the number compared to 2000, which was accounted for 17. Asia and Africa, represent the highest rates of urbanization, mainly because of the two reasons; an increase in a natural population, and rural to urban. Urbanization may result in the rise of energy consumption, degrade the environment, increases energy-related greenhouse gas emissions, and exacerbated global warming (Creutzig, Baiocchi, Bierkandt, Pichler, \& Seto, 2015; Güneralp et al., 2017; Kennedy, Ramaswami, Carney, \& Dhakal, 2009).

Urbanization leads to an increase in the urban population and causes an upserge in energy consumption in rural areas. Besides, the urban area's labor force contributes to the production sector leading to a further increase in energy consumption. Energy consumption up surging has manifold implications for the environment and human health; especially energy based on fossil fuel degrades the atmospheric environment, and negatively affects human health. Poor air quality has a significant impact on the health of many urban residents, and unsightly put a layer of dust on plants, buildings, and other surfaces. The ground facts support that half of the world population nowadays live in urban areas. Cities almost consume $50 \%$ of overall energy and produce almost $60 \%$ of carbon dioxide emission that provides input to overall global warming. However, the rapid increase in $\mathrm{CO}_{2}$ emission has been reported from the developing economies, especially, the Asian Region with China and India at top of the list since 2005. Therefore, an appropriate energy policy along with urbanization holds a combinatory status.

Trade is also a key determinant that affects the energy consumption level of the country. In this regard, footprints about the effect of trade openness on renewable and non-renewable have been addressed in the body of literature. The effect of trade on aggregate energy consumption is relatively rich as compared to renewable energy only. Similarly, Khan, Yu, Belhadi, and Mardani (2020) argue that international trade has positive nexuses with the country's renewable energy. The study suggests international trade with a special focus on renewable energy. The growth in renewable energy can be vital to maintain and enhance environmental sustainability (Ponce \& Khan, 2021). While discussing the relationship of trade liberalization with energy consumption. It was observed that liberalization encourages renewable energy that resultantly accounts for environmental sustainability (Ponce \& Khan, 2021). While in another study, Ponce and Khan (2021) report that trade activities mainly focusing on renewable energy consumption contribute to $\mathrm{CO}_{2}$ reduction in developed nations of the world.

According to Wu, Bazer, Cudd, Meininger, and Spencer (2004), 'China's growth miracle since the 1980s, there has been a rapid increase in urbanization. The country's urbanization rate, during the period from 1978 to 2012 increased from 17.92-52.57\%. As per China Statistical Bureau (2012), the 
population of urban increased by 10 million, and newly 498 cities were recognized in the same period. Thus, China is shifting from an industrial urban society to an agricultural society (Deng et al., 2008; Lin, 2002). This increased urbanization has consequently resulted in problems for environmental protection, and energy savings. According to China Energy Statistical Yearbook (CESY, 2012), consumption of energy increased from 410.1 million tons of oil equivalent (Mote) in 1980, to 2735.2 mote in 2012. According to World Bank (2015) report, China has become the world's largest emitter of greenhouse gases, showing a vigorous growth from 1467 megatons in1980, to 8287 megatons in the year 2010.

A more recent forecast by the International Energy Agency, showing continuous growth and forecast that energy consumption in China will reach 5500 mote, almost double the US level, and will account for more than a quarter of the world's total energy consumption by 2040 . According to China Energy Statistical Yearbook (CESY, 2012), $60 \%$ of this energy, in China was consumed in cities, and on average energy consumed in the urban population individually is on average 1.3 times that consumed by the rural population. However, increasing the usage of petrol and the burning of coal has caused serious problems with public health. As per statistics, more than one million people died in China from air pollution created by transportation. The main source behind is cars as a source of PM 2.5, and haze weather every year, which the central government and local authorities both consider the most important environmental problem. Besides, urbanization China gains significant achievement in world trade, according to the Center for Strategic and World Bank (2015), the share of China in exports was $13.45 \%$ in 2015 , and China achieved double digits economic growth for a decade. Both trade and urbanization may have significant implications for energy consumption in China.

Although urbanization and energy are extensively discussed by many studies (Abbasi \& Riaz, 2016; Al-mulali, Sab, \& Fereidouni, 2012; Ewing \& Rong, 2008; M. S. Hossain, 2011; K. Jones, 1989; Lariviere \& Lafrance, 1999; Parikh \& Shukla, 1995; Poumanyvong \& Kaneko, 2010b). However, there is still lack of consensus. Most of these studies focused on the urbanization, and energy consumption relationship and few studies investigated how urbanization affects renewable and non-renewable energy consumption. While in the existing body of knowledge some studies explored the relationship between urbanization and energy consumption in China (Dhakal, 2009; Liu, 2009; O'Neill, Ren, Jiang, \& Dalton, 2012; Poumanyvong \& Kaneko, 2010a; C. Zhang \& Y. J. E. p. Lin, 2012). Some of the studies noticed that more trade activities result in more renewable and non-renewable energy consumption (Akbar, Yuelan, Maqbool, Zia, \& Saeed, 2021). While, exploring the nexus between urbanization, and energy consumption some studies pointed that urbanization can cause more energy consumption in the country (Guo \& Pachauri, 2017; Keho, 2016). Due to this prevailing gap, the motivation of the paper has been raised purely by studying the relevant literature. As none of the studies exists that simultaneously focuses on the relationship of trade openness and urbanization with renewable, and non-renewable energy consumption.

The study contributes to the existing literature from the following aspects. Firstly, most of the previous studies discussed either renewable energy or nonrenewable energy consumption with trade policy separately, however trade may affect both renewable energy, and non-renewable energy consumption. Therefore, this study contributes to the literature by adding both types of energy consumption in a single study which may provide detailed insight into the degree of influence of trade openness for both renewable energy or non-renewable energy consumptions in China. Secondly, the results of this study provide information about the relative degree of renewable and nonrenewable energy consumption in response to trade openness and urbanization in China. Thirdly, we use the Quantile Regression technique for the empirical analysis; which may provide more comprehensive information on trade and urbanization policies for both renewable and non-renewable energy consumption in different quantiles.

As the above paragraph clearly chalk out the claim of this research being a novel work as the previous letreature do not offer any robust study that explores the impact of both trade and urbanization on renwable and non-renwable energy consumption in the context of China, and it is evident from the statistics that China gained remarkable upsurge in both trade liberty and urbanization which have shifted the energy consumption curve of all types in the country. Perhaps, the magnitude of effect of the trade and urbanization on renewable and non-renewable energy is not exactly known in the chinees case. Therfore, this study aims to analyze the effect of trade openness and urbanization on renewable and non-renewable energy consumption in China.

The rest of paper is senthesized as the second section describes literature while third and fourth section show the hypothesis development and stylized trends respectively. The fifth section contains the dimensions of the methodology while sixth and seventh section eleborate the empirical results and conclusion of the study.

\section{Empirical Literature Review}

Urbanization has been largely discussed in the literature, Moomaw and Shatter (1996), urban development consists of threefold meaning: urban concentration, urban primacy, and urbanization population. In the empirical literature, the population share of big cities is measured in terms of urban concentration, and the shares of big cities in the country population are measured by urban primacy, while the total urban population consists of the shares of the big cities in the country. Williamson (1965), and Wheaton and Shishido (1981) postulate that urban concentration initially increases with economic growth and will decline later. However, Ades and Glaeser (1995) assert that labor forces are correlated positively with urban concentration. Urbanization could influence energy consumption in three ways. Firstly, social aspects including household consumption and economic development such as industrial expansion and production could lead to higher energy consumption in the economy (D. W. Jones, 1991; Madlener \& Sunak, 2011; Parikh \& Shukla, 1995; Sadorsky, 2014a); and (Madlener \& Sunak, 2011; Phetkeo Poumanyvong, Shinji Kaneko, \& Shobhakar Dhakal, 2012).

Secondly, the complicated linkage of social process, economic process, and technological process, which make the urbanization greater contribution to energy consumption as a unit of measurement. However, the economic process means the shifting of agricultural society less intensive to urban society with high energy-intensive. K. Jones (1989), state that commercial and industrial activities havebeen increased in cities, which result in greater use of energy, particularly in industries of manufacturing and production, to compete with demand-supply, and rely on intensive energy usage (Sadorsky, 
2014a). Improved transportation grid in cities results in increased demand for transportation energy Phetkeo Poumanyvong et al. (2012)]. The use of electrical appliances, like air conditioners, lighting, and others is pretty much greater as compared to rural residents. However, improved technological development could improve energy efficiency (Ye, Cheng, Wang, Lin, \& Ren, 2013).

Thirdly, solid policy and interventions can change the course of energy usage in urbanization process development (Bernardini \& Galli, 1993; Malenbaum \& Malenbaum, 1978). However, the fact that more urbanized cities have an edge of enhanced regulation and governance to adopt technology that aims more energy-saving (Madlener \& Sunak, 2011). Al-mulali et al. (2012) report a bi-directional long-run relationship between usage and process of urbanization This was further supported by Phetkeo Poumanyvong et al. (2012)], who argued that in low-income countries urbanization helps in the reduction of energy consumptions, compared with high-income countries where it promotes more energy consumption. Similarly, Phetkeo Poumanyvong et al. (2012) support this by arguing that increase transportation in urbanization results in more energy consumptions. Lariviere and Lafrance (1999), and Ewing and Rong (2008) report a positive association between urbanization and energy consumption. While, M. S. J. E. P. Hossain (2011) explores nine developing countries and reporte a negative relationship between energy consumption and the urbanization process. The negative relationship indicates that the urbanization process may contain new technologies that consume less energy.

There is rich literature available on $\mathrm{CO}_{2}$ and energy consumption. The recent statistics show a greater contribution of trade activities in $\mathrm{CO}_{2}$ emissions. According to the Energy Information Administration (EIA) report; 75 percent of increased $\mathrm{CO}_{2}$ emissions have been recorded from 1980 to 2012 . Whereas, international trade increased by 450 percent for the same period (EIA, 2013; WDI, 2015). However, Sieminski (2013) indicates that developing countries have a greater contribution to the $\mathrm{CO}_{2}$ emissions, and predicted an anticipated 127 percent increase by the year 2020 .

The nexus of trade openness and $\mathrm{CO}_{2}$ emissions are discussed from a different perspective such as composition effect, technological advancement, and industrialization (Farhani, Shahbaz, \& Reviews, 2014; Ullah, Ali, et al., 2019b). Many developed and developing countries have adopted trade liberalization in different periods; which resulted in industrialization and resulted in larger $\mathrm{CO}_{2}$ emissions. Besides, the trade liberalization encompasses green technologies that may not increase $\mathrm{CO}_{2}$ emissions. Ref. Sebri and Ben-Salha (2014), in developing countries recently the transfer of renewable energy technologies plays a more effective role in less $\mathrm{CO}_{2}$ emissions. However, Mukhopadhyay (2009) asserts trade openness as an effective factor contributes to $\mathrm{CO}_{2}$ emissions and thereby contributing to energy consumption. A. Jalil and S. F. J. E. p. Mahmud (2009), K. Jayanthakumaran, R. Verma, and Y. J. E. P. Liu (2012), Farhani et al. (2014), and E. J. R. Dogan and Reviews (2015) confirm a positive relationship between trade and $\mathrm{CO}_{2}$ emissions. The empirical results of Shahbaz, Uddin, Rehman, Imran, and Reviews (2014)], report a long-run relationship between real income, $\mathrm{CO}_{2}$ emission, trade openness, and energy consumption. They applied an ARDL model and found that trade openness and energy consumption positively contribute to carbon emissions, suggesting long-run bidirectional causality between energy consumption and carbon emissions, and also reported a similar relationship between $\mathrm{CO}_{2}$ emission and trade liberalization. While, ref.Farhani and Shahbaz (2014), also report a bidirectional causality between $\mathrm{CO}_{2}$ emissions and energy consumption, and with unidirectional causality running from economic growth and trade openness to $\mathrm{CO}_{2}$ emissions in the long run.

On the other hand, opting for renewable energy with environment-friendly technologies like solar energy, wind energy and geothermal may reduce $\mathrm{CO}_{2}$ emission (Zeeshan et al., 2021). Various empirical studies like Jebli, Youssef, and Ozturk (2016) argue that renewable energy may play a very important role in achieving a higher growth rate and a sustainable environment. They used 24 sub-Sahara African countries for analysis and found that renewable energy consumption mitigation of emission and trade can encourage renewable energy source consumption which will ultimately decrease $\mathrm{CO}_{2}$ emission. Zhang, Chen, and Zhang (2018), also state that in China air pollution is the world's fourth main threat to the crisis of human health, damaging of environment, and economy. Moreover, Abdullah, Azam, and Zakariya (2016), Ullah, Ali, et al. (2019b), and Ullah, Rehman, et al. (2019) report that CO 2 emissions lead to an increase the health expenditures.

The dynamic nexus of trade with both renewable and non-renewable energy has been explored in the prevailing literature. In this regard, Akbar et al. (2021) argue that trade openness positively affects both types of energy consumptions i.e., renewable and non-renewable energy consumption. Likewise, Parsa and Sajjadi (2017)], also proclaim the significant nexus of trade openness with energy consumption. Similarly, Khoshnevis Yazdi and Shakouri (2017) highlight the significant role of trade openness in enhancing the volume of both renewable, and non-renewable energy consumption in the South African context. Likewise, Guo and Pachauri (2017), while using data from 78 countries assert that urbanization increases energy consumption. However, (Adom, Bekoe, Amuakwa-Mensah, Mensah, \& Botchway, 2012) state that economic growth has ineffective relationship with both renewable and nonrenewable energy consumption in iran, more precisely the study finds neither decreasing energy consumption nor changing energy portfolio affects the economic growth. Ref. [2021] confirm a unidirectional impact of the economic growth on renewable energy consumption in the context of Sauidi Arabia. Hanif (2018) validate the contribution of energy consumption, consists of both traditional and renewable energy consumption can contribute to economic growth in the East Asia and Pasific regions. Likewise, Hdom and Fuinhas (2020) confirm a bidirectional causality between trade openness and energy consumption in the context of Brazil and suggest the use of renewable energy as it is effective in reducing $\mathrm{CO} 2$ emmission.While, in similar investigation a mix results have been reported and over all both types of energies are found friendly to the economic growth (Awodumi \& Adewuyi, 2020).

The nexus between urbanization and energy consumption have been explored in the body of knowledge (Shahbaz, Loganathan, Zeshan, \& Zaman, 2015). Likewise, Azam, Khan, Zaman, and Ahmad (2015) commend that urbanization tends to increase the level of energy consumption in Greece. Similarly, (Adom et al., 2012) also postulate that urbanization is a key determinant that enhances the volume of energy consumption in the country. Likewise, Keho (2016) consideres urbanization as a key driver that promotes the level of energy consumption in African countries. 


\title{
3. Hypothesis Development And Conceptual Framework
}

\author{
H1: Trade Openness Increase Renewable and Non-Renewable Energy Consumption
}

The first hypothesis tests whether trade openness increases renewable and non-renewable energy consumption in China. There is the possibility that trade openness can either increase nonrenewable energy, renewable energy, or both type of energy consumption. Many previous studies have documented the relationship of trade with renewable and non-renewable energy consumption. The outcomes of most of the previous studies suggest a positive relationship between energy consumption and trade such as Shahbaz, Uddin, Rehman, and Imran (2014), and Eyup Dogan and Turkekul (2016) report positive nexus between trade and energy consumption. Likewise, many other studies also report a similar possitive relationship of trade with energy consumption (Farhani \& Shahbaz, 2014; A. Jalil \& S. F. Mahmud, 2009). Similarly, trade also show in many previous studies contributing to the amount of renewable energy consumption in many countries and regions (Fotros \& Maaboudi, 2010; Ullah, Ali, et al., 2019a). This study uses Quantile Regression to test this hypothesis, besides granger causality is also used to verify the baseline estimations.

\section{H2: Urbanization Increases Renewable and Non-Renewable Energy Consumption}

The second hypothesis tests the urbanization effect on renewable and nonrenewable energy consumption, urbanization may affect either renewable energy, non-renewable energy, or both type of energy consumption. Many studies have investigated the urbanization nexus with energy consumptions (Lariviere \& Lafrance, 1999; C. Zhang \& Y. Lin, 2012). Many other studies also document similar footprints (Jedwab, 2013; Madlener \& Sunak, 2011; P Poumanyvong, S Kaneko, \& S Dhakal, 2012; Yang, Zhang, \& Zhang, 2016). Conversely, Zhou et al. (2012) validate a negative relationship between urbanization and energy consumption. The contradiction in findings may arises due to the nature of data, methods, and stages of development of the country. This study applies Quantile Regression to test this hypothesis, and granger causality to validate and verify the Quantile Regression results.

\section{Trade Openness, Urbanization, And Energy Consumption In China}

The shifting of conventional agriculture society to a more advanced urban society has resulted in environmental and energy-saving problems in China (Deng et al., 2008; Lin, 2002). This increase grew from 410.1 million tons of oil equivalent in the year 1980 to 2735 mote in 2012 , evident from (China Energy Statistical Yearbook, 2012). While according to the International Energy Agency report China is the world's largest greenhouse gas emitter. Growth of 1467 megatons to 8287 megatons for the period 1980 to 2010 was reported. The reason greatly relies upon the fact that more than $60 \%$ of the energy consumed in China was in cities, and individually consumed energy by the urban population is 1.3 times that of rural pollution (CESY, 2012). Public health is facing serious problems due to the increase in the use of fossil fuels and according to China Energy statistics, almost one million people died from transportation created due to air pollution in big cities like Beijing, Tianjin, and Guangzhou. Recognizing the importance of promoting green energy today is one of the key missions of the government in China. In the year 2009, a national-level policy developed by the central government primarily aimed to promote the development of an environment-friendly society. The essential element is to protect the environment, reducing emissions, and saving energy in urban policy development.

Urbanization promotes living standards and economic growth, however, it also resulted in increased consumption of energy. In China, the cities have surpassed the industrial sector and became the largest consumers of energy. Energy consumption has increased with urbanization in three pathways: in the transport and new buildings sector; the increasing use of energy-intensive transportation; changing energy-intensive lifestyle with the rising quality of energy. However, the fact that $50 \%$ more consumption of energy in urban households as compared to rural household's consumption indicates that this increase will promote more national level energy growth consumption in China. Policies to implement green building, friendly environment energy vehicles, for greater concern with awareness among population is needed to save energy consumption and maximize effort for reduction. Lifestyle changes and e-society are emerging challenges to energy-saving policies for climate initiatives in China.

Figure 2 depicts the relationship of trade $(\mathrm{T})$ with the response to renewable (RE) and non-renewable energy (NRE). A very strange relationship exists in the context of China among these variables. From 1990 there is an increasing trend for non-renewable energy and a continuous decreasing pattern of practices for renewable energy is seen. However, trade despite the increasing trend for non-renewable and decreasing trend for renewable energy. The figure shows that renewable energy consumption in China is decreasing over the period from 1990 to 2011, then onward a slight upward curve has been witnessed in the graph. This determines that a very indifferent response of trade to renewable, and non-renewable energy is exhibited in the above figure 2. The growing needs of energy are increasingly met by a diversified energy mix.

The energy demand slows dramatically after the new policies scenario to 1 percent per year on average in China since 2000 (See figure 2 ), this is mainly due to the economic structural shifts, and the result of solid efficient energy policies. However, electricity and renewable are interlinked closely, but the share of total generation of coal falls notably in recent years intending to drop down up to 40 percent less by the year 2040 . On the other hand, natural gas and electricity are closely connected to residential and industrial sectors which shows the fossil fuel contribution to residential energy. China world's biggest oil consumer, but despite the fact of increasing demand for fuel consumption in transport, the ownership of passenger vehicles slows in recent years due to adaptation of renewable energy sectors including automobiles; according to the China energy statistics among one in four cars on road in the country are predicted to be by electric by the year 2040. With the policy support that continues to lower down the cost for renewables, PV solar becomes electricity generation's cheapest source in the light of the New Policies Scenario and it has a less adverse impact on the environment and attaining sustainable development.

\section{Model, Methods, And Data}




\subsection{Model}

This study uses two models to analyze the impact of trade and urbanization on renewable and non-renewable energy in China as follow

$$
\begin{aligned}
N R E_{t}=\beta_{0}+\beta_{1} G D P_{t}+\beta_{2} T_{t}+\beta_{3} U r b_{t}+\beta_{3} P_{o p}+\mu_{1 t} . \\
\mu_{t} \sim \text { n.i.i.d }\left(0, \sigma^{2}\right), \\
R E_{t}=\beta_{0}+\beta_{1} G D P_{t}+\beta_{2} T_{t}+\beta_{3} U r b_{t}+\beta_{3} P_{o p}+\mu_{2 t} . \\
\mu_{t} \sim \text { n.i.i.d }\left(0, \sigma^{2}\right),
\end{aligned}
$$

In the above equations NRE shows non-renewable energy, RE is used for renewable energy, T is trade openness, Urb presents urbanization, and Pop shows population, while $\mu_{1 t}$ and $\mu_{2 t}$ represents error terms of models 1 and 2 respectively. The first model shows the urbanization and trade effect on non-renewable energy consumption, we used non-renewable energy consumption as the dependent variable while urbanization and trade openness are taken as dependent variables, population and urbanization are taken as control variables. The second model shows urbanization and trade effect on renewable energy consumption, we used trade and urbanization as the independent variable, and renewable energy is chosen as the dependent variable, GDP and population are taken as control variables.

\subsection{Methodology}

We adopt the Quantile Regression method for analysis, which provides estimations of dependent variables in the response of explanatory variables at different points of the dependent variable's conditional distribution (Eide \& Showalter, 1998). The standard least squares regression technique for estimation is based on the average effect of the independent variables on the dependent variable, and regression gives a summary for the averages of the distributions corresponding to the set of independent variables (Coad \& Rao, 2008). The conventional regression estimates exhibit the model-based conditional mean of a dependent variable, however, we can estimate several regressions corresponding to the various percentage points of the distributions, thus get a more complete picture of the set.

The simple regression is based on the mean while the Quantile Regression method is based on the conditional median (Koenker \& Bassett Jr, 1978). The Quantile Regression analyses capture several responses of the dependent variable due to the changes in independent variables (Jareño, de la 0 González, Tolentino, \& Sierra, 2020; F. Jareño, R. Ferrer, \& S. Miroslavova, 2016a; F. Jareño, R. Ferrer, \& S. J. A. E. Miroslavova, 2016b; Sevillano \& Jareño, 2018). The Quantile Regression estimates depict a more complete description of estimations, and it allows us to estimate the heterogeneous effect of dependent variables due to the variations in the explanatory variables in different quantiles (Anh, Kreinovich, \& Thach, 2017). For example, we can assess the effect of the explanatory variables for the dependent variables in the 10th or 95th quantile. Also, the Quantile Regression does not follow the restrictive assumption of the identical distribution of error terms Ferrando, Ferrer, and Jareño (2017), and the Quantile Regression provides more robust estimations even if outliers exist in data (Jareño et al., 2016b). Perusing the Koenker and Bassett Jr (1978) style we follow the following equation for Quantile Regression

$$
y_{i}=x_{i} \beta_{\theta}+u_{i \theta}
$$

In the above equation, $Y i$ is the dependent variable, $x i$ is independent variables, $\mathrm{k} x 1$ vector, $\beta_{\theta}$ the unknown $\mathrm{k} \times 1$ vector of estimated regression parameters for values of $\theta$ (range from 0 to 1), and $u_{i \theta}$ is the error term of the model assumed to be uncorrelated with $x i$ Jareño et al. (2020). We can rewrite the conditional quantile of $Y i$ given $x i$ as follows

$$
Q_{\theta}\left(y_{i} / x_{i}\right)=x_{i} \beta_{\theta}
$$

Koenker and Bassett Jr (1978)] purposed quantile estimation by minimization of equation 4 as follow

$$
\underset{\beta \epsilon \Re^{k}}{\operatorname{Min}} \sum_{t \in\left[\mathbb{K} t: y>x_{t}\right]} \theta\left|y_{t}-\dot{x}_{t} \beta\right|+\sum_{t: y>x_{t}^{\prime}}(1-\theta)|| y_{t}-\dot{x}_{t} \beta||
$$

In the above equation $y t$ shows the dependent variable, $\mathrm{x}$ is the explanatory variables of $k$ by 1 vector, $\beta$ is the coefficient vector and 1 is the quantile to be estimated. The coefficient vector $\beta$ will differ depending on the particular quantile being estimated. The Quantile Regression method uses the generalized method of moments or linear programming with the simplex algorithm for estimations Sevillano and Jareño (2018). Equation 5 minimizes the weighted error terms and distributes the appropriate weight according to the chosen quantile (Jareño et al., 2020; Jareño et al., 2016b; Sevillano \& Jareño, 2018). We can rewrite equation 5 by utilizing the Quantile Regression method as follows:

$$
\begin{aligned}
& N R P=\beta_{0}^{\theta}+\beta_{1}^{\theta} G D P+\beta_{2}^{\theta} T+\beta_{3}^{\theta} U r b+\beta_{4}^{\theta} P o p++\epsilon_{t} \quad \ldots .(6) \\
& R E_{t}=\beta_{0}^{\theta}+\beta_{5}^{\theta} G D P+\beta_{6}^{\theta} T+\beta_{7}^{\theta} U r b+\beta_{8}^{\theta} P o p+\epsilon_{t} \quad \ldots .(7)
\end{aligned}
$$

$\beta_{i}^{\theta} \mathrm{i}=0,1,2,4$ represents the Quantile Regression coefficients for the model in which non-rentable energy is the dependent variable. Where $\beta_{i}^{\theta} \mathrm{i}=4,6,7$, and 8 show the coefficients of the model. Renewable energy is the dependent model. $\theta$ th indicates the number of Quantile Regressions that ranges from 0.1 to 0.9. The data of variables have been obtained from different sources including World Bank indicators, National Bureau of Statistics PR. China, 
International Energy Associations (IEA) for the period 1990-2018, table 1 provides a detail of the variables, unit, and source. In many time-series studies somehow a similar time is taken (Rehman et al., 2021; Ullah, Ali, et al., 2019a; Zeeshan et al., 2021). We selected this time frame as China featured tremendous growth during this span.

\subsection{Data and Variables}

Table No 1: Data and Variables

\begin{tabular}{|c|c|c|c|}
\hline Variable & Acronyms & Unit & Sources \\
\hline Gross domestic production & GDP & GDP (constant 2010 US\$) & $\begin{array}{l}\text { World Bank Development } \\
\text { Indicators }\end{array}$ \\
\hline Urbanization & Urb & Rural to urban urbanization (Per 10 thousand) & $\begin{array}{l}\text { National Bureau of Statistics, PR. } \\
\text { China }\end{array}$ \\
\hline Population & Pop & Population growth (annual \%) & $\begin{array}{l}\text { World Bank Development } \\
\text { Indicators }\end{array}$ \\
\hline Trade openness & $\mathrm{T}$ & Trade (\% of GDP) & $\begin{array}{l}\text { World Bank Development } \\
\text { Indicators }\end{array}$ \\
\hline $\begin{array}{l}\text { Non-renewable Energy } \\
\text { Consumption }\end{array}$ & NRE & Fossil fuel energy consumption (\% of total) & International Energy Association \\
\hline Renewable Energy Consumption & RE & $\begin{array}{l}\text { Renewable energy consumption (\% of total final energy } \\
\text { consumption) }\end{array}$ & International Energy Association \\
\hline
\end{tabular}

\section{Results And Discussion}

Table 2: Unit Root Tests

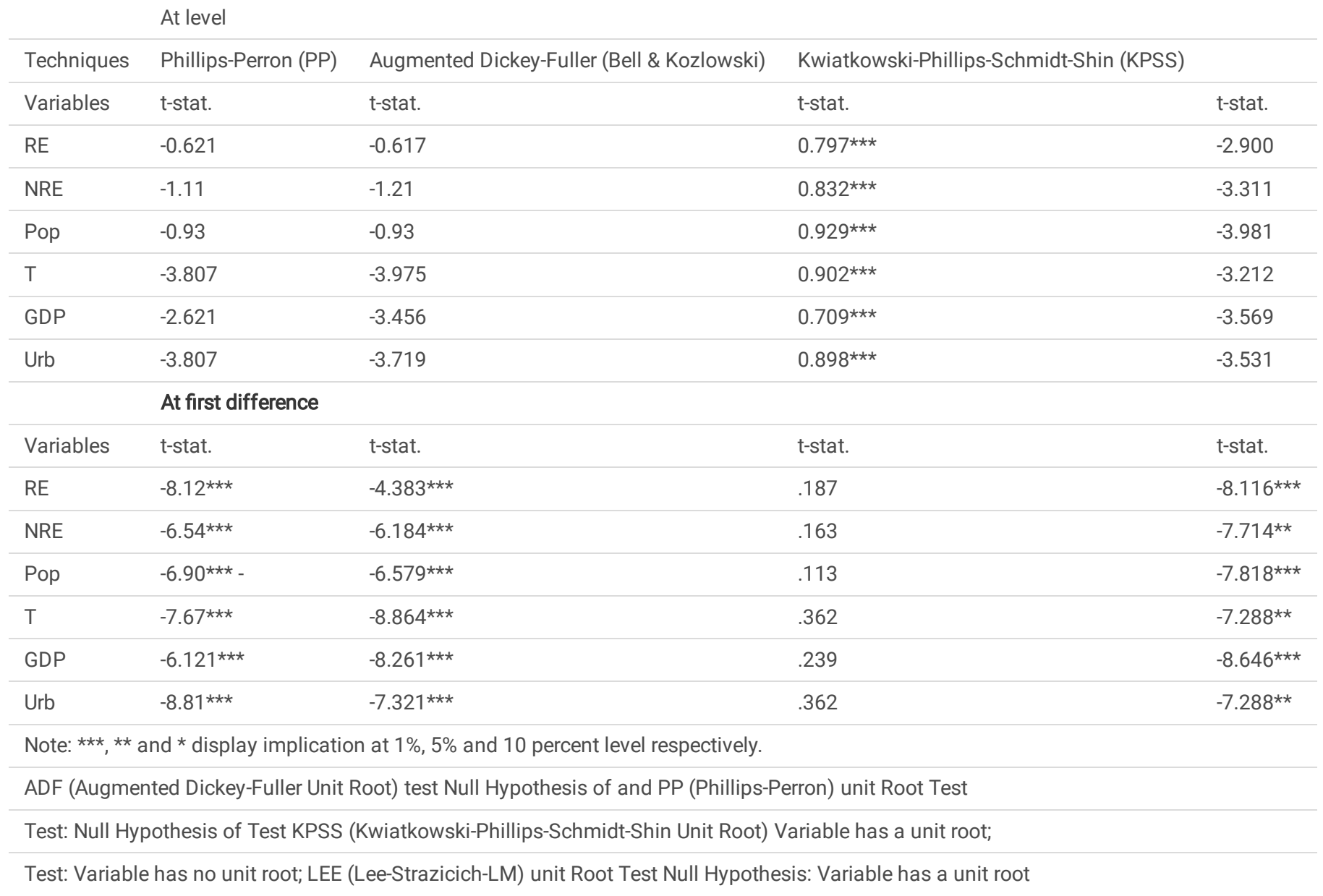


Our empirical findings are based on Quantile Regression; the main aim of this study is to investigate the trade openness and rural urbanization effect on renewable and renewable energy consumption in China. We split our analysis into different models for renewable energy and non-renewable energy. Table 2 presents unit root test for stationary check including Phillips-Perron (PP) Augmented Dickey-Fuller (Bell \& Kozlowski) Kwiatkowski-PhillipsSchmidt-Shin (KPSS). All unit root test shows that all variables are non-stationary at the level and become stationary at first differences, which indicates that renewable energy, non-renewable energy, and trade openness have a long-run relationship.

Table 3 shows Quantile Regression estimations of the non-renewable energy model; where GDP, urbanization, population, and trade are taken as independent variables, while non-renewable energy consumption is the dependent variable. GDP has a positive and significant association with nonrenewable energy consumption from $1^{\text {st }}$ to $9^{\text {th }}$ quantiles. All the coefficients are significant at the 1 percent level. This implies that energy consumption is a fundamental factor in aggregate productivity, though each sector of the economy requires energy, the manufacturing industries require a high level of energy consumption. Urbanization showing a positive association with non-renewable energy consumption from 1st to 9th Quantile, but most of the coefficients are insignificant except $1^{\text {st }}, 3^{\text {rd }}$ and $6^{\text {th }}$ quantiles that show a significant effect on the energy consumption. This implies that urbanization has a minor effect on non-renewable energy consumption in China, and it somehow contradicts the previous studies' findings as many previous studies reported a positive association between urbanization and non-renewable energy consumption (Guo \& Pachauri, 2017; Keho, 2016). One possible reason could be that previous studies in the context of China used residential energy consumption variables rather than aggregate consumption.

The 1st, 3rd, and 6th quantiles show positive and significant effect of urbanization on non-renewable energy consumption While Population positively and significantly affecting the non-renewable energy consumption from $1^{\text {st }}$ quantile to $7^{\text {th }}$ quantile of the regression. This means that with an increase in population, the non-renewable energy consumption also increases which implies that most of the energy consumption of the household is based on the non-renewable energy inputs. Trade and energy have a positive and significant association with non-renewable energy consumption from 1 st quantile to 9th quantile. The majority of the coefficients are strongly significant, and most of the quantiles are significant at a 1 percent level of significance. This indicates that trade activities are major contributors to non-renewable energy consumption, it further implies that most of the trade activities, particularly exports require a high volume of energy consumption. The findings of this study are supported by various previous studies (Abbasi \& Riaz, 2016; Eyup Dogan, 2015; Farhani \& Shahbaz, 2014; A. Jalil \& S. F. Mahmud, 2009; K. Jayanthakumaran, R. Verma, \& Y. Liu, 2012; Shahbaz, Uddin, Rehman, \& Imran, 2014).

Table No 3: Quintile Regression when non-renewable Energy Consumption is used as dependent variable

\begin{tabular}{|c|c|c|c|c|c|c|c|c|c|}
\hline Variable & 0.1 & 0.2 & 0.3 & 0.4 & 0.5 & 0.6 & 0.7 & 0.8 & 0.9 \\
\hline \multirow[t]{2}{*}{ GDP } & $6.56321^{\star \star \star}$ & 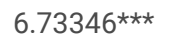 & $6.75066^{\star \star \star}$ & $7.06769 * \star \star *$ & 7.18601 *** & $7.34595^{\star \star \star}$ & $7.46756^{\star \star \star}$ & 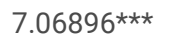 & 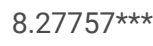 \\
\hline & $(0.00)$ & $(0.00)$ & $(0.00)$ & $(0.00)$ & $(0.00)$ & $(0.00)$ & $(0.00)$ & $(0.00)$ & $(0.00)$ \\
\hline Urb & $0.00078^{*}$ & 0.00058 & $0.00067^{\star}$ & 0.00032 & 0.00058 & $0.00079 *$ & 0.00053 & 0.00014 & 0.00023 \\
\hline \multirow[t]{2}{*}{ Pop } & 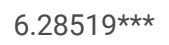 & $4.85477^{\star \star *}$ & $5.14099 \star \star \star$ & $5.67466^{\star \star \star}$ & $6.41563^{\star \star \star}$ & $7.06319 * *$ & $7.21941 * \star$ & 5.50301 & 7.94904 \\
\hline & $(0.00)$ & $(0.02)$ & $(0.01)$ & $(0.00)$ & $(0.00)$ & $(0.02)$ & $(0.05)$ & $(0.28)$ & $(0.22)$ \\
\hline
\end{tabular}

Note: In parenthesis, we show probability values, $\star \star \star$ indicates significance level at $1 \%,{ }^{\star \star}$, means significance level at $5 \%$ and $*$ is the significance level at $1 \%$ probability level.

Table No 4: Quintile Regression when Renewable Energy Consumption is used as dependent variable 


\begin{tabular}{|c|c|c|c|c|c|c|c|c|c|}
\hline Variable & 0.1 & 0.2 & 0.3 & 0.4 & 0.5 & 0.6 & 0.7 & 0.8 & 0.9 \\
\hline \multirow[t]{2}{*}{ GDP } & $0.68762^{\star \star \star}$ & $0.73518^{\star \star \star}$ & 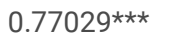 & $0.76812^{\star \star \star}$ & $0.79105^{\star \star \star}$ & 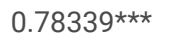 & $0.85169 * \star \star$ & 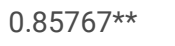 & 0.64862 \\
\hline & $(0.00)$ & $(0.00)$ & $(0.00)$ & $(0.00)$ & $(0.00)$ & $(0.00)$ & $(0.00)$ & $(0.02)$ & $(0.20)$ \\
\hline \multirow[t]{2}{*}{ Urb } & 0.00152 & 0.00201 & 0.00184 & $0.00202^{\star}$ & 0.00156 & 0.00317 & 0.00256 & 0.00580 & $0.01023^{\star \star}$ \\
\hline & $(0.41)$ & $(0.17)$ & $(0.12)$ & $(0.10)$ & $(0.34)$ & $(0.20)$ & $(0.48)$ & $(0.20)$ & $(0.05)$ \\
\hline \multirow[t]{2}{*}{ Pop } & $28.12597^{\star \star \star}$ & $27.48321^{\star \star \star ~}$ & $28.80096^{\star \star \star}$ & $29.05493^{\star \star \star \star}$ & $28.98995^{\star \star \star}$ & $30.94363^{\star \star \star}$ & $27.81474^{\star \star \star}$ & 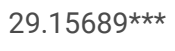 & 34.26362 \\
\hline & $(0.00)$ & $(0.00)$ & $(0.00)$ & $(0.00)$ & $(0.00)$ & $(0.00)$ & $(0.00)$ & $(0.00)$ & $(0.01)$ \\
\hline \multirow[t]{2}{*}{$\mathrm{T}$} & $0.160686^{\star \star \star}$ & $0.117693^{\star \star}$ & 0.123324 ** & $0.120755^{\star}$ & 0.12648 & 0.094244 & 0.065124 & -0.00556 & 0.056321 \\
\hline & $(0.00)$ & $(0.04)$ & $(0.04)$ & $(0.06)$ & $(0.14)$ & $(0.36)$ & $(0.70)$ & $(0.97)$ & $(0.83)$ \\
\hline
\end{tabular}

Table 4 represents the Quantile Regression for renewable energy as the dependent variable, and explanatory variables are the same as in table 1, i.e. GDP, urbanization, population, and trade liberalization are the explanatory variable. GDP shows a significant and positive impact on renewable energy consumption from $1^{\text {st }}$ to $8^{\text {th }}$ quantile, the $9^{\text {th }}$ quantile is insignificant. This implies that an increase in GDP increases renewable energy consumption or in other words that aggregate productivity leads to increase renewable energy consumption. Urbanization has a positive and significant effect on renewable energy consumption only in the $9^{\text {th }}$ quantile. The rest of the quantiles (from $1^{\text {st }}$ to $8^{\text {th }}$ ) have an insignificant association. This implies that rural to urban urbanization is not the main factor influencing renewable energy consumption. The results contradict previous studies' findings due to factors, such as the data and methodologies used, and the non-consideration of differences in the stage of development (Poumanyvong \& Kaneko, 2010a). Besides, the majority of previous studies consider a homogenous effect for all the countries, which is not true because of the differences in developmental stages and infrastructure across countries.

The population shows a positive and significant effect on renewable energy consumption from $1^{\text {st }}$ quantile to $8^{\text {th }}$ quantile, while the $9^{\text {th }}$ quantile is showing an insignificant coefficient. This shows that an increase in population leads to an increase in renewable energy consumption that implies that most of the energy consumption of the households is consistent with renewable energy consumption. Trade has mix effect on renewable energy consumption; from 1 st quantile to $4^{\text {th }}$, trade openness shows a positive significant effect on the renewable energy consumption, while from 5 th quantile to 9th quantile trade demonstrates an insignificant effect on renewable energy consumption, this implies that trade openness partially contributes to the renewable energy consumption. Besides, a minor contribution of renewable energy indicates that most of the export production units consist of nonrenewable energy use, and it could be evident that most of the manufacturing industries heavily rely on fossil fuel energy consumption. These empirical findings are in line with many previous studies Sebri and Ben-Salha (2014), Rahman and Vu (2020), and (Zeren \& Akkuş, 2020).

Figure 4 represents the coefficients of the estimated model using the Quantile Regression in table 3. The red lines show the confidence interval of the relevant coefficient while the blue lines depict the estimated coefficients. Figure 4 estimates indicate that all the coefficients such as urbanization, trade openness, population, and GDP lies between the confidence levels. This implies that coefficients of all variables are stable and accurately predicting nonrenewable energy consumption. Similarly, the coefficients are given in figure 2, also have the same results as all the coefficients such as urbanization, trade openness, population and GDP lies between the confidence levels. These results confirm that explanatory variables have stable coefficients that lie within a confidence level indicating that all variables are accurately predicting renewable consumption in China.

Tables 5, and 6, presents the heterogeneity of estimated Quantile Regression; this test verifies that each quantile has a specific effect on the dependent variable. Therefore, to test the heterogeneity of the sensitivity of renewable and non-renewable energy effects at different stages for the included explanatory variables such as GDP, Population, trade, and urbanization. Table 4, contains the heterogeneity test for non-renewable energy-dependent variable estimates while table 5 , shows the heterogeneity results for renewable energy. The test reports the null hypothesis of equal coefficients of estimations at the usual significance levels for the included independent variables and quantile pairs. We reject the null hypothesis for both renewable and non-renewable cases. The results imply the heterogeneous response of renewable and non-renewable energy due to the explanatory variables in each quantile. Moreover, this test validates the baseline Quantile Regression results considering the results of the quantile as suitable and appropriate estimation techniques (Sevillano \& Jareño, 2018).

Non - RE Table 5 Test of the heterogeneity of the Quantile Regression estimates 


\begin{tabular}{llll} 
Quantiles & Variable & Restr. Value & Prob. \\
\hline $0.1,0.2$ & GDP & -0.170246 & 0.7247 \\
\hline $0.3,0.4$ & GDP & -0.317025 & 0.1898 \\
\hline $0.5,0.6$ & GDP & -0.159939 & 0.7457 \\
\hline $0.7,0.8$ & GDP & 0.398606 & 0.6881 \\
\hline $0.8,0.9$ & GDP & -1.208616 & 0.4898 \\
\hline $0.1,0.2$ & URB & 0.000205 & 0.6659 \\
\hline $0.3,0.4$ & URB & 0.000349 & 0.1352 \\
\hline $0.5,0.6$ & URB & -0.000209 & 0.4933 \\
\hline $0.7,0.8$ & URB & 0.000385 & 0.4706 \\
\hline $0.8,0.9$ & URB & $-8.77 \mathrm{E}-05$ & 0.9033 \\
\hline $0.1,0.2$ & POP & 1.430413 & 0.3793 \\
\hline $0.3,0.4$ & POP & -0.533667 & 0.5901 \\
\hline $0.5,0.6$ & POP & -0.647560 & 0.7432 \\
\hline $0.7,0.8$ & POP & 1.716406 & 0.6143 \\
\hline $0.8,0.9$ & POP & -2.446032 & 0.6436 \\
\hline $0.1,0.2$ & T & 0.025053 & 0.2108 \\
\hline $0.3,0.4$ & T & -0.004570 & 0.7207 \\
\hline $0.5,0.6$ & T & -0.001491 & 0.9270 \\
\hline $0.7,0.8$ & T & 0.017576 & 0.5851 \\
\hline $0.8,0.9$ & T & 0.010014 & 0.8334
\end{tabular}

RE-Table 6 Test of the heterogeneity of the Quantile Regression estimates 


\begin{tabular}{|c|c|c|c|}
\hline Quantiles & Variable & Restr. Value & Prob. \\
\hline $0.1,0.2$ & GDP & 2.621280 & 0.4825 \\
\hline $0.3,0.4$ & GDP & 0.399664 & 0.9040 \\
\hline $0.5,0.6$ & GDP & 4.545886 & 0.1551 \\
\hline $0.6,0.7$ & GDP & 0.567574 & 0.8050 \\
\hline $0.7,0.8$ & GDP & -1.623508 & 0.3466 \\
\hline $0.8,0.9$ & GDP & -0.287414 & 0.8350 \\
\hline $0.1,0.2$ & URB & -0.000913 & 0.4647 \\
\hline $0.3,0.4$ & URB & 7.71E-05 & 0.9354 \\
\hline $0.4,0.5$ & URB & -0.000596 & 0.5556 \\
\hline $0.6,0.7$ & URB & $-9.80 \mathrm{E}-06$ & 0.9907 \\
\hline $0.8,0.9$ & URB & -0.001459 & 0.1356 \\
\hline $0.1,0.2$ & POP & 5.883515 & 0.5140 \\
\hline $0.2,0.3$ & POP & -2.058540 & 0.8040 \\
\hline $0.4,0.5$ & POP & 12.98520 & 0.1360 \\
\hline $0.6,0.7$ & POP & 1.632477 & 0.8006 \\
\hline $0.8,0.9$ & POP & -2.386153 & 0.5892 \\
\hline $0.1,0.2$ & $\mathrm{~T}$ & 0.090758 & 0.3478 \\
\hline $0.3,0.4$ & $\mathrm{~T}$ & 0.011941 & 0.8968 \\
\hline $0.5,0.6$ & $\mathrm{~T}$ & 0.139068 & 0.1444 \\
\hline $0.7,0.8$ & $\mathrm{~T}$ & -0.020695 & 0.7206 \\
\hline $0.8,0.9$ & $\mathrm{~T}$ & 0.023509 & 0.6928 \\
\hline
\end{tabular}

\section{Conclusion}

China has made significant improvements in its trade volume and has a significant contribution to the world trade market. Since China obtained the status of WTO member, it has achieved double-digit economic growth. With the passage of time china showed tremendous expansion in its trade liberty and expansion of trade activities that significantly substantiated the use of both renewable and non-renewable energy options. Besides, repaid urbanization, government momentum also put pressure on the available energy resources. Therefore, this study investigates renewable, and nonrenewable energy consumption in response to trade liberalization, and urbanization in China.

We applied the Quantile Regression method for the empirical analysis, as this estimator could provide a clearer picture of trade activities, and urbanization in response to energy consumption on different points. Our results show that trade activities significantly increase non-renewable energy consumption while it partially contributes to renewable energy consumption. Urbanization affects non-energy consumption in three quantiles, while it contributes to renewable energy consumption in a single quantile. It indicates that urbanization is not the main influencing factor responsible for energy consumption in China. These results contradict the previous studies' findings due to various reasons such as different data; variables and methodologies by considering the same stage of development.

Based on the empirical findings some policy implications can be considered. Firstly, the trade activities lead to an increase in industrial production, and exports thus enhance the use of non-renewable and renewable energy consumption. In this regard, special policies should be made to enhance trade and urbanization with sustainable environmental performance. Secondly, the insignificant association between trade and renewable energy suggests that trade activities in production and export commodities heavily rely on non-renewable energy inputs instead of renewable energy. Coping with this, the government should exercise more use of renewable energy consumption for environmental efficiency. Indeed, renewable energy could affect local production, but the export sector which accounts for large-scale production, relay on non-renewable energy resources which is not a good sign for the environment. Non-renewable energy resources could have serious environmental implications on society and may impede long-term sustainable development. Therefore, the government needs to implement certain regulations while expanding trade to control the negative effect of non-renewable energy consumptions. Besides, the government needs to increase the share of renewable energy in the industrial production, and export sector which could have a good impact on country trade, and further account for a friendly environment along with sustainable performance. Besides, the government may support exporting firms to use renewable energy in the production process; for example, tax incentives or subsidizing the industrial inputs with a view to encouraging the use of renewable energy consumption with a special focus. 
This study has certain limitations as it comprises urbanization, trade, population, and economic growth variables for analysis, one may consider some additional variables such as domestic resources abundance, exporting and non-exporting industries, etc. Moreover, this study could be extended by analyzing the household, and industrial level data for different provinces in China. The same variables can be tested for developing, and developed countries' panels to provide robust insight into the existing body of literature.

\section{Declarations}

\section{Compliance with ethical standards}

Ethical Approval: All authors declare that they have no conflict of interest

Consent to participate: This study does not involve animals or human objects.

Consent to publish. We have read the author's guide, rules, and ethics for publication in Environmental Science and Pollution Research.

All authors agree for the manuscript to be published in Environmental Science and Pollution Research

Author contribution: Muhammad Zeeshan: conceptualization, data curation, writing the original draft. JiaBin Han: data curation,

visualization, writing review, and editing. Alam Rehman: methodology, visualization, supervision, editing. Irfan Ullah: review and editing. Fakhr E Alam Afradi writing review and editing and software.

Funding: : The innovation and talents project of the university in Liaoning (WR2019016).

Data availability: The data that support the findings of this study are openly available on request.

COMPETING INTERESTS: The authors have declared that there is no competing interest regarding this manuscript.

ACKNOWLEDGEMENT: I would like to extend my thankfulness to my supervisor Dr. Jiabin Han for his help and guidance in making sure this work has been carried out in a timely and suitable way.

\section{References}

1. Abbasi, F., \& Riaz, K. (2016). CO2 emissions and financial development in an emerging economy: an augmented VAR approach. Energy policy, 90, 102-114.

2. Abdullah, H., Azam, M., \& Zakariya, S. K. (2016). The impact of environmental quality on public health expenditure in Malaysia. Asia Pacific journal of Advanced business social studies, 2(2), 365-379.

3. Ades, A. F., \& Glaeser, E. L. (1995). Trade and circuses: explaining urban giants. The Quarterly Journal of Economics, $110(1), 195-227$.

4. Adom, P. K., Bekoe, W., Amuakwa-Mensah, F., Mensah, J. T., \& Botchway, E. (2012). Carbon dioxide emissions, economic growth, industrial structure, and technical efficiency: Empirical evidence from Ghana, Senegal, and Morocco on the causal dynamics. Energy, 47(1), 314-325.

5. Akbar, M. W., Yuelan, P., Maqbool, A., Zia, Z., \& Saeed, M. (2021). The nexus of sectoral-based CO 2 emissions and fiscal policy instruments in the light of Belt and Road Initiative. Environmental Science and Pollution Research, 1-15.

6. Al-mulali, U., Sab, C. N. B. C., \& Fereidouni, H. G. (2012). Exploring the bi-directional long run relationship between urbanization, energy consumption, and carbon dioxide emission. Energy 46(1), 156-167.

7. Anh, L. H., Kreinovich, V., \& Thach, N. N. (2017). Econometrics for financial applications (Vol. 760): Springer.

8. Awodumi, O. B., \& Adewuyi, A. O. (2020). The role of non-renewable energy consumption in economic growth and carbon emission: Evidence from oil producing economies in Africa. Energy strategy reviews, 27, 100434.

9. Azam, M., Khan, A. Q., Zaman, K., \& Ahmad, M. (2015). Factors determining energy consumption: Evidence from Indonesia, Malaysia and Thailand. Renewable and Sustainable Energy Reviews, 42, 1123-1131.

10. Bell, B. S., \& Kozlowski, S. W. (2002). Adaptive guidance: Enhancing self-regulation, knowledge, and performance in technology-based training. Personnel Psychology, 55(2), 267-306.

11. Bernardini, O., \& Galli, R. (1993). Dematerialization: long-term trends in the intensity of use of materials and energy. Futures 25(4), 431-448.

12. CESY. (2012). China Energy Statistical Yearbook Retrieved from

13. Coad, A., \& Rao, R. (2008). Innovation and firm growth in high-tech sectors: A quantile regression approach. Research policy, 37(4), $633-648$.

14. Creutzig, F., Baiocchi, G., Bierkandt, R., Pichler, P.-P., \& Seto, K. C. (2015). Global typology of urban energy use and potentials for an urbanization mitigation wedge. Proceedings of the national academy of sciences, 112(20), 6283-6288.

15. Deng, J., Jiang, J., Zhang, Y., Lin, X., Du, C., \& Xiong, Y. (2008). FeVO4 as a highly active heterogeneous Fenton-like catalyst towards the degradation of Orange II. Applied Catalysis B: Environmental 84(3-4), 468-473.

Page $12 / 17$ 
16. Dhakal, S. J. E. p. (2009). Urban energy use and carbon emissions from cities in China and policy implications. 37(11), 4208-4219.

17. Dogan, E. (2015). The relationship between economic growth and electricity consumption from renewable and non-renewable sources: A study of Turkey. Renewable Sustainable Energy Reviews 52, 534-546.

18. Dogan, E., \& Turkekul, B. (2016). CO 2 emissions, real output, energy consumption, trade, urbanization and financial development: testing the EKC hypothesis for the USA. Environmental Science Pollution Research 23(2), 1203-1213.

19. Dogan, E. J. R., \& Reviews, S. E. (2015). The relationship between economic growth and electricity consumption from renewable and non-renewable sources: A study of Turkey. 52, 534-546.

20. Eide, E., \& Showalter, M. H. (1998). The effect of school quality on student performance: A quantile regression approach. Economics letters 58(3), 345-350.

21. Ewing, R., \& Rong, F. (2008). The impact of urban form on US residential energy use. Housing policy debate 19(1), 1-30.

22. Farhani, S., \& Shahbaz, M. (2014). What role of renewable and non-renewable electricity consumption and output is needed to initially mitigate CO2 emissions in MENA region? Renewable Sustainable Energy Reviews 40, 80-90.

23. Ferrando, L., Ferrer, R., \& Jareño, F. (2017). Interest Rate Sensitivity of S panish Industries: A Quantile Regression Approach. The Manchester School 85(2), 212-242.

24. Fotros, M. H., \& Maaboudi, R. (2010). The impact of trade openness on CO2 emissions in Iran, 1971-2005.

25. Güneralp, B., Zhou, Y., Ürge-Vorsatz, D., Gupta, M., Yu, S., Patel, P. L., . . Seto, K. C. (2017). Global scenarios of urban density and its impacts on building energy use through 2050. Proceedings of the National Academy of Sciences, 114(34), 8945-8950.

26. Guo, F., \& Pachauri, S. (2017). China's Green Lights Program: A review and assessment. Energy policy, 110, 31-39.

27. Hanif, I. (2018). Impact of fossil fuels energy consumption, energy policies, and urban sprawl on carbon emissions in East Asia and the Pacific: A panel investigation. Energy strategy reviews, 21, 16-24.

28. Hdom, H. A., \& Fuinhas, J. A. (2020). Energy production and trade openness: Assessing economic growth, $\mathrm{CO} 2$ emissions and the applicability of the cointegration analysis. Energy strategy reviews, 30, 100488.

29. Hossain, M. S. (2011). Panel estimation for CO2 emissions, energy consumption, economic growth, trade openness and urbanization of newly industrialized countries. Energy Policy 39(11), 6991-6999.

30. Jalil, A., \& Mahmud, S. F. (2009). Environment Kuznets curve for CO2 emissions: a cointegration analysis for China. Energy policy $37(12), 5167-5172$.

31. Jareño, F., de la O González, M., Tolentino, M., \& Sierra, K. (2020). Bitcoin and gold price returns: A quantile regression and NARDL analysis. Resources Policy 67, 101666.

32. Jareño, F., Ferrer, R., \& Miroslavova, S. (2016a). US stock market sensitivity to interest and inflation rates: a quantile regression approach. Applied Economics, 48(26), 2469-2481.

33. Jayanthakumaran, K., Verma, R., \& Liu, Y. (2012). CO2 emissions, energy consumption, trade and income: a comparative analysis of China and India Energy Policy 42, 450-460.

34. Jebli, M. B., Youssef, S. B., \& Ozturk, I. J. E. I. (2016). Testing environmental Kuznets curve hypothesis: The role of renewable and non-renewable energy consumption and trade in OECD countries. 60, 824-831.

35. Jedwab, R. (2013). Urbanization without structural transformation: Evidence from consumption cities in Africa. George Washington University, Washington, DC. Processed

36. Jones, D. W. (1991). How urbanization affects energy-use in developing countries. Energy policy 19(7), 621-630.

37. Jones, K. (1989). Right turn: The conservative revolution in education: Hutchinson Radius London.

38. Keho, Y. (2016). What drives energy consumption in developing countries? The experience of selected African countries. Energy policy, $91,233-246$.

39. Kennedy, C. A., Ramaswami, A., Carney, S., \& Dhakal, S. (2009). Greenhouse gas emission baselines for global cities and metropolitan regions. Paper presented at the Fifth Urban Research Symposium, Cities and Climate Change: Responding to an Urgent Agenda.

40. Khan, S. A. R., Yu, Z., Belhadi, A., \& Mardani, A. (2020). Investigating the effects of renewable energy on international trade and environmental quality. Journal of environmental Management, 272, 111089.

41. Khoshnevis Yazdi, S., \& Shakouri, B. (2017). Renewable energy, nonrenewable energy consumption, and economic growth. Energy Sources, Part B: Economics, Planning, and Policy, 12(12), 1038-1045.

42. Koengkan, M. (2018). The positive impact of trade openness on consumption of energy: Fresh evidence from Andean community countries. Energy, 158, 936-943.

43. Koenker, R., \& Bassett Jr, G. J. E. j. o. t. E. S. (1978). Regression quantiles. 33-50.

44. Lariviere, I., \& Lafrance, G. (1999). Modelling the electricity consumption of cities: effect of urban density. Energy economics 21(1), 53-66.

45. Lin, N. (2002). Social capital: A theory of social structure and action (Vol. 19): Cambridge university press.

46. Liu, Y. J. E. (2009). Exploring the relationship between urbanization and energy consumption in China using ARDL (autoregressive distributed lag) and FDM (factor decomposition model). 34(11), 1846-1854.

47. Madlener, R., \& Sunak, Y. (2011). Impacts of urbanization on urban structures and energy demand: What can we learn for urban energy planning and urbanization management? Sustainable cities society 1(1), 45-53. 
48. Malenbaum, W., \& Malenbaum, W. (1978). World demand for raw materials in 1985 and 2000: McGraw-Hill New York.

49. Moomaw, R. L., \& Shatter, A. M. (1996). Urbanization and economic development: a bias toward large cities? Journal of Urban Economics 40(1), 1337.

50. Mukhopadhyay, K. (2009). Trade and the Environment: Implications for Climate Change. Decision 36(3).

51. O'Neill, B. C., Ren, X., Jiang, L., \& Dalton, M. J. E. E. (2012). The effect of urbanization on energy use in India and China in the iPETS model. 34, S339S345.

52. Parikh, J., \& Shukla, V. (1995). Urbanization, energy use and greenhouse effects in economic development: Results from a cross-national study of developing countries. Global environmental change 5(2), 87-103.

53. Parsa, H., \& Sajjadi, S. Z. (2017). Exploring the trade openness, energy consumption and economic growth relationship in Iran by Bayer and Hanck combined cointegration and causality analysis. Iranian Economic Review, 21(4), 829-845.

54. Ponce, P., \& Khan, S. A. R. (2021). A causal link between renewable energy, energy efficiency, property rights, and CO2 emissions in developed countries: A road map for environmental sustainability. Environmental Science and Pollution Research, 1-14.

55. Poumanyvong, P., \& Kaneko, S. (2010a). Does urbanization lead to less energy use and lower CO2 emissions? A cross-country analysis. Ecological Economics, 70(2), 434-444.

56. Poumanyvong, P., Kaneko, S., \& Dhakal, S. (2012). Impacts of urbanization on national transport and road energy use: Evidence from low, middle and high income countries. Energy Policy 46, 268-277.

57. Rahman, M. M., \& Vu, X.-B. (2020). The nexus between renewable energy, economic growth, trade, urbanisation and environmental quality: A comparative study for Australia and Canada. Renewable Energy.

58. Rehman, A., Ullah, I., Ullah, Z., Zeeshan, M., Hussain, A., \& Rahman, H. U. (2021). Adoption of green banking practices and environmental performance in Pakistan: A demonstration of structural equation modelling. Environment, Development and Sustainability, 1-21.

59. Sadorsky, P. (2011). Trade and energy consumption in the Middle East. Energy Economics, 33(5), 739-749.

60. Sadorsky, P. (2014a). The effect of urbanization and industrialization on energy use in emerging economies: Implications for sustainable development. American Journal of Economics Sociology 73(2), 392-409.

61. Sadorsky, P. (2014b). The effect of urbanization on CO2 emissions in emerging economies. Energy Economics, 41, 147-153.

62. Sebri, M., \& Ben-Salha, O. (2014). On the causal dynamics between economic growth, renewable energy consumption, CO2 emissions and trade openness: Fresh evidence from BRICS countries. Renewable Sustainable Energy Reviews 39, 14-23.

63. Sevillano, M. C., \& Jareño, F. (2018). The impact of international factors on Spanish company returns: a quantile regression approach. Risk Management 20(1), 51-76.

64. Shahbaz, M., Loganathan, N., Zeshan, M., \& Zaman, K. (2015). Does renewable energy consumption add in economic growth? An application of auto-regressive distributed lag model in Pakistan. Renewable Sustainable Energy Reviews 44, 576-585.

65. Shahbaz, M., Uddin, G. S., Rehman, I. U., \& Imran, K. (2014). Industrialization, electricity consumption and CO2 emissions in Bangladesh. Renewable Sustainable Energy Reviews 31, 575-586.

66. Shahbaz, M., Uddin, G. S., Rehman, I. U., Imran, K. J. R., \& Reviews, S. E. (2014). Industrialization, electricity consumption and C02 emissions in Bangladesh. 31, 575-586.

67. Shi, D. (2015). Understanding China's energy strategy and its sustained economic growth: present and future. China Finance Economic Review, 3(1), $1-8$.

68. Sieminski, A. (2013). International energy outlook 2013. Retrieved from

69. Ullah, I., Ali, S., Shah, M. H., Yasim, F., Rehman, A., \& Al-Ghazali, B. M. (2019a). Linkages between Trade, CO2 Emissions and Healthcare Spending in China. International journal of environmental research public health 16(21), 4298.

70. Ullah, I., Ali, S., Shah, M. H., Yasim, F., Rehman, A., \& Al-Ghazali, B. M. (2019b). Linkages between Trade, CO2 Emissions and Healthcare Spending in China. International Journal of Environmental research Public Health, 16(21), 4298.

71. Ullah, I., Rehman, A., Khan, F. U., Shah, M. H., Khan, F., \& Management. (2019). Nexus between trade, CO2 emissions, renewable energy, and health expenditure in Pakistan. The International Journal of Health Planning 35(4), 818-831.

72. Wheaton, W. C., \& Shishido, H. (1981). Urban concentration, agglomeration economies, and the level of economic development. Economic development cultural change 30(1), 17-30.

73. Williamson, J. G. (1965). Antebellum urbanization in the American Northeast. The Journal of Economic History 25(4), $592-608$.

74. World Bank. (2015). World Bank Report. Retrieved from

75. Wu, G., Bazer, F. W., Cudd, T. A., Meininger, C. J., \& Spencer, T. E. (2004). Maternal nutrition and fetal development. The Journal of nutrition 134(9), 2169-2172.

76. Yang, J., Zhang, W., \& Zhang, Z. (2016). Impacts of urbanization on renewable energy consumption in China. Journal of Cleaner Production 114, 443451.

77. Ye, L., Cheng, Z., Wang, Q., Lin, W., \& Ren, F. (2013). Overview on green building label in China. Renewable Energy 53, $220-229$. 
78. Zeeshan, M., Han, J., Alam Rehman, H. B., Farooq, N., Waseem, M., Hussain, A., . . Ahmad, I. (2021). Nexus between Foreign Direct Investment, Energy Consumption, Natural Resource, and Economic Growth in Latin American Countries. International Journal of Energy Economics and Policy, 11(1), 407-416.

79. Zeren, F., \& Akkuş, H. T. (2020). The relationship between renewable energy consumption and trade openness: New evidence from emerging economies. Renewable Energy, 147, 322-329.

80. Zhang, C., \& Lin, Y. (2012). Panel estimation for urbanization, energy consumption and CO2 emissions: A regional analysis in China. Energy policy $49,488-498$.

81. Zhang, C., \& Lin, Y. J. E. p. (2012). Panel estimation for urbanization, energy consumption and CO2 emissions: A regional analysis in China. 49, 488498.

82. Zhang, X., Chen, X., \& Zhang, X. J. P. o. t. N. A. O. S. (2018). The impact of exposure to air pollution on cognitive performance. $115(37)$, $9193-9197$.

83. Zhou, W., Zhu, B., Chen, D., Griffy-Brown, C., Ma, Y., \& Fei, W. (2012). Energy consumption patterns in the process of China's urbanization. Population Environment 33(2-3), 202-220.

\section{Figures}

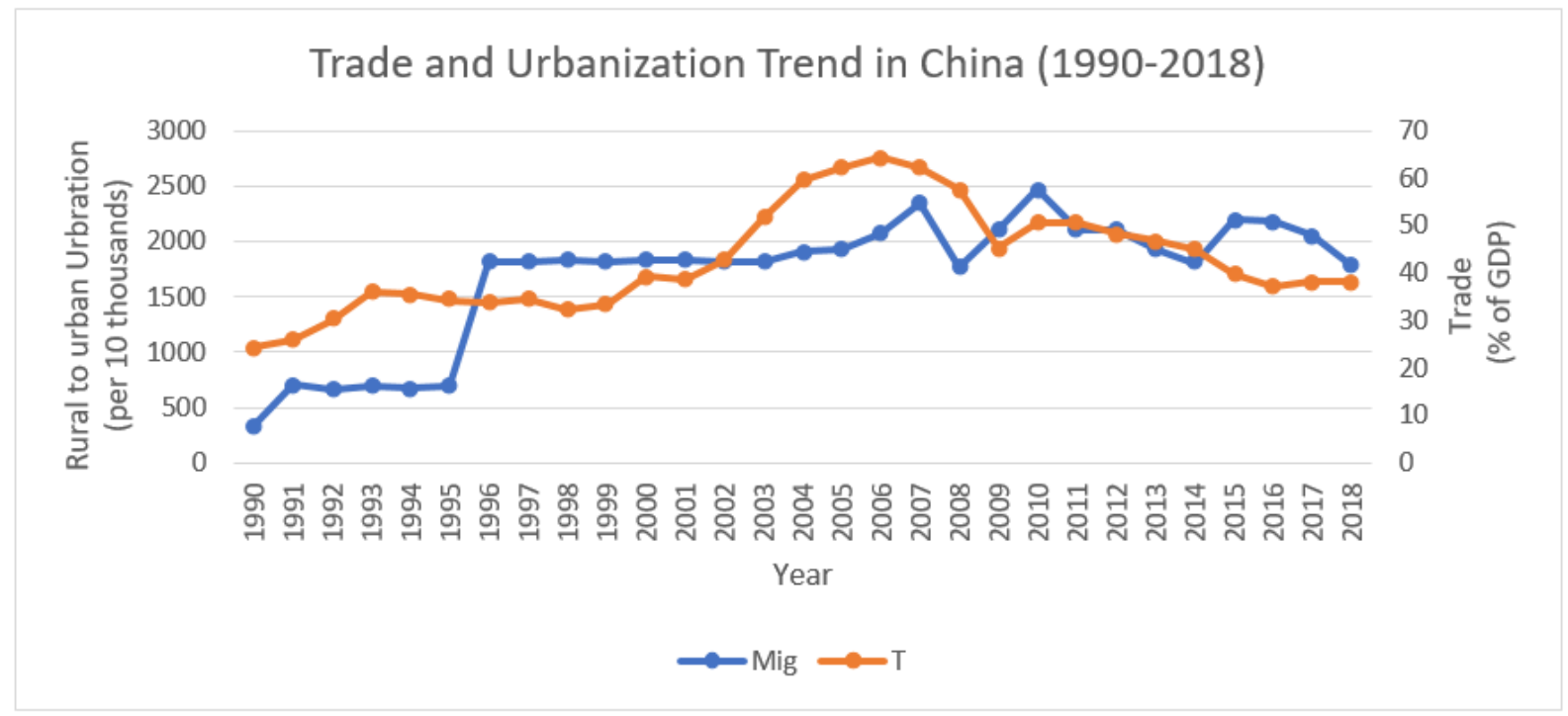

Figure 1

Trade and Urbanization Source: WDI

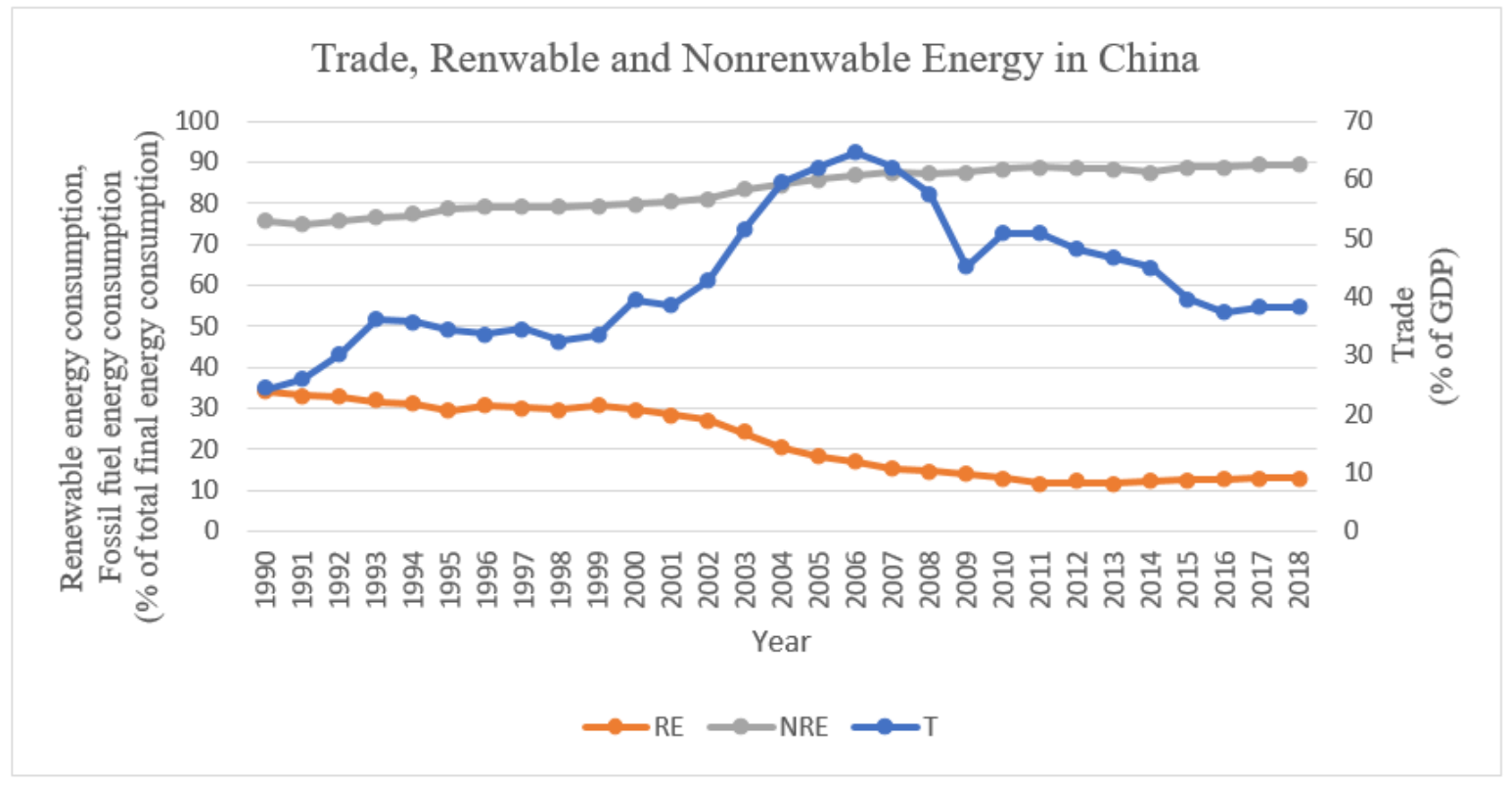

Figure 2 
T

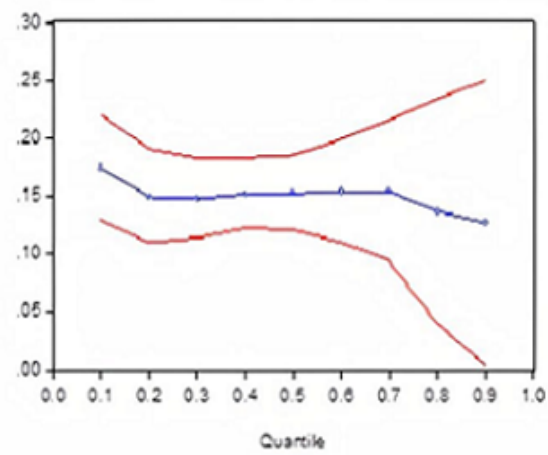

URB

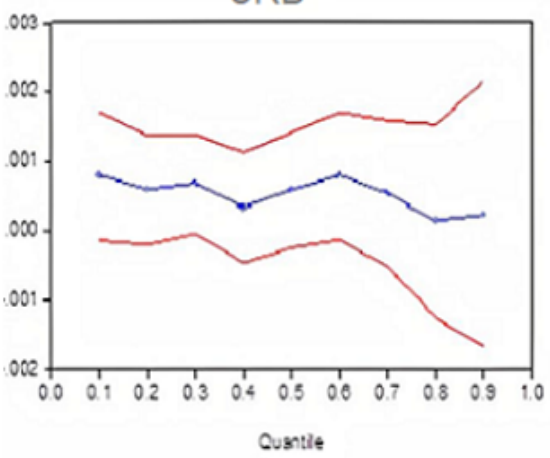

LOG(GDP1)

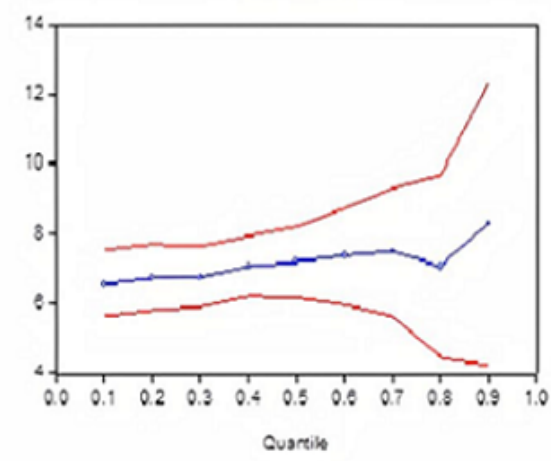

POP2

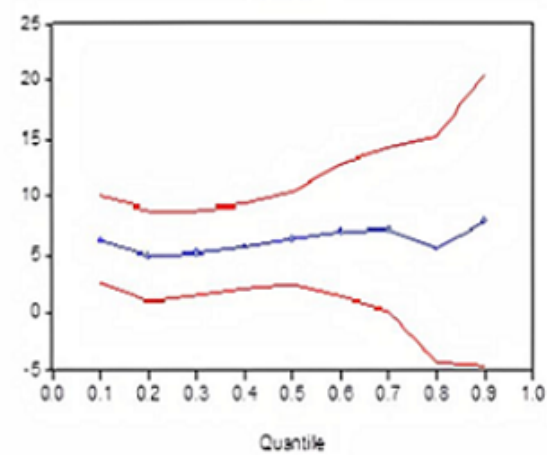

Figure 3

Quantile Process Estimates (Non-Renewable Energy Consumption Model) Impacts of changes in the explanatory variables on non-renewable energy consumption across quantiles Notes: The blue line denotes the QR coefficient estimates, while the red lines show confidence intervals at 90 percent level of significance.

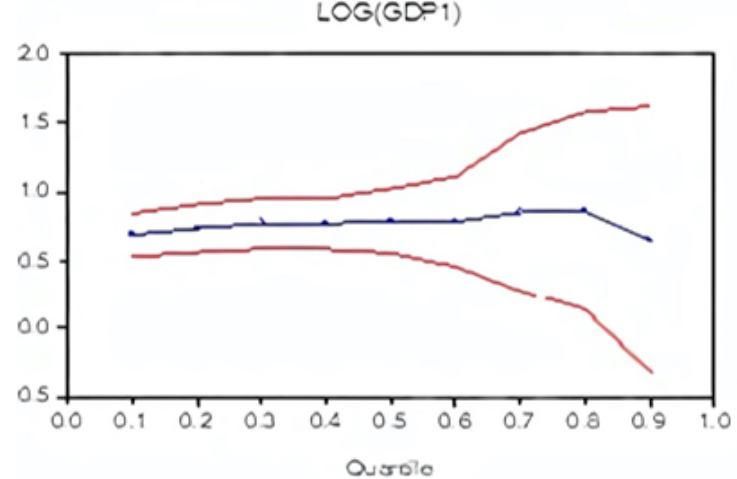

LOG(FOF2)

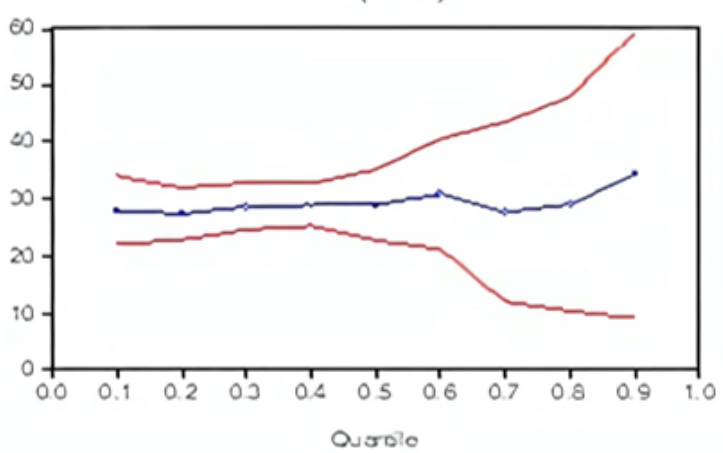

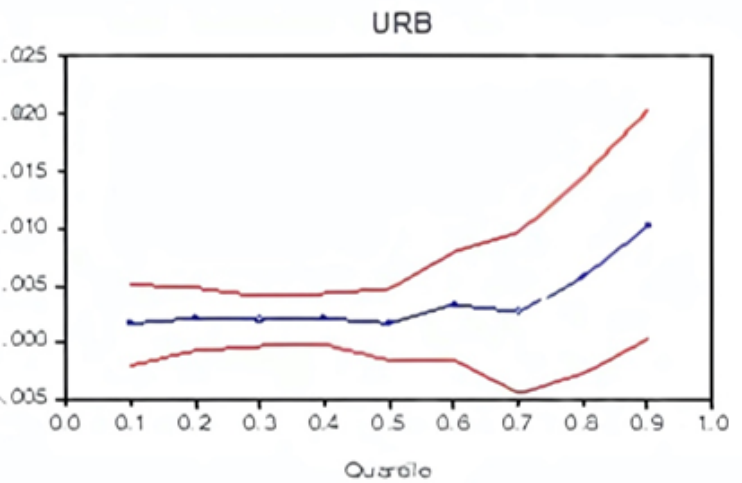

T

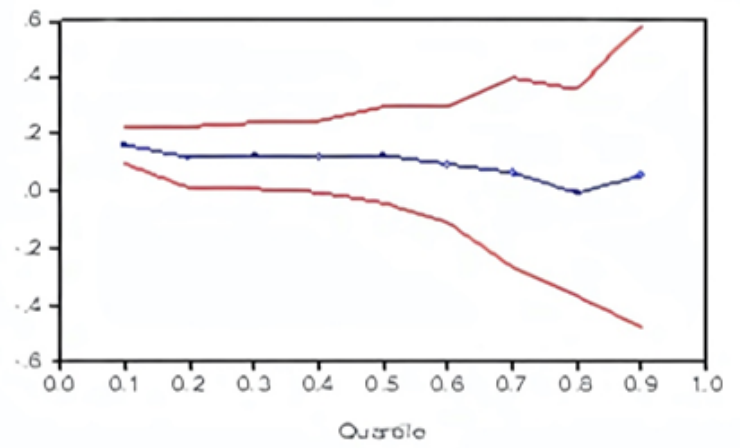


Quantile Process Estimates (Renewable Energy Consumption Model) Impacts of changes in the explanatory variables on renewable energy consumption across quantiles Notes: The blue line denotes the QR coefficient estimates, while the red lines show confidence intervals at a 90 percent level of significance.

\section{Supplementary Files}

This is a list of supplementary files associated with this preprint. Click to download.

- Appendix.docx 